\title{
Early and midterm results of thoracic endovascular aortic repair using a branched endograft for aortic arch pathologies: A retrospective single-center study
}

Tomoaki Kudo, MD, PhD, ${ }^{\mathrm{a}}$ Toru Kuratani, MD, PhD, ${ }^{\mathrm{b}}$ Kazuo Shimamura, MD, PhD, ${ }^{\mathrm{b}}$ and Yoshiki Sawa, MD, $\mathrm{PhD}^{\mathrm{a}}$

\section{ABSTRACT}

Background: Zone o landing hybrid thoracic endovascular aortic repair (TEVAR) includes a few moderately invasive surgical procedures. To reduce invasiveness, TEVAR with a branched aortic arch stent-graft can be considered. This study aimed to elucidate the effectiveness of performing TEVAR using a Bolton (Bolton Medical, Inc, Sunrise, Fla) branched endograft by analyzing early and midterm results.

Methods: We enrolled 28 patients (mean age, 78.4 years) who underwent TEVAR with the Bolton branched endograft in Osaka University Hospital between October 2012 and June 2018 with a mean follow-up period of 4.0 years. Double-side and single-side branched devices were used in $24(85.7 \%)$ and $4(14.3 \%)$ patients, respectively.

Results: All procedures were successful; no cases of endoleak or conversion to open repair were noted during the 30-day postoperative period. The perioperative stroke rate was $14.3 \%$ ( 4 out of 28 ); midterm stroke was not detected. All patients with perioperative stroke had atheroma grade $\geq 2$ in the brachiocephalic artery. No type 1a endoleak was reported during the early or midterm results. The cumulative survival rate, aorta-related death-free rate, and aortic event-free survival rate at 5 years were $80.8 \%, 95.8 \%$, and $81.6 \%$, respectively.

Conclusions: We achieved satisfactory early and midterm results by using a Bolton branched endograft for high-risk patients with arch pathologies except for high postoperative stroke. Although this treatment method is associated with postoperative stroke, performing strict evaluation of atheroma may prevent such complication. By preventing intraoperative stroke, TEVAR with this custom-made Bolton branched endograft may be considered a less-invasive treatment. (JTCVS Techniques 2020;4:17-25)

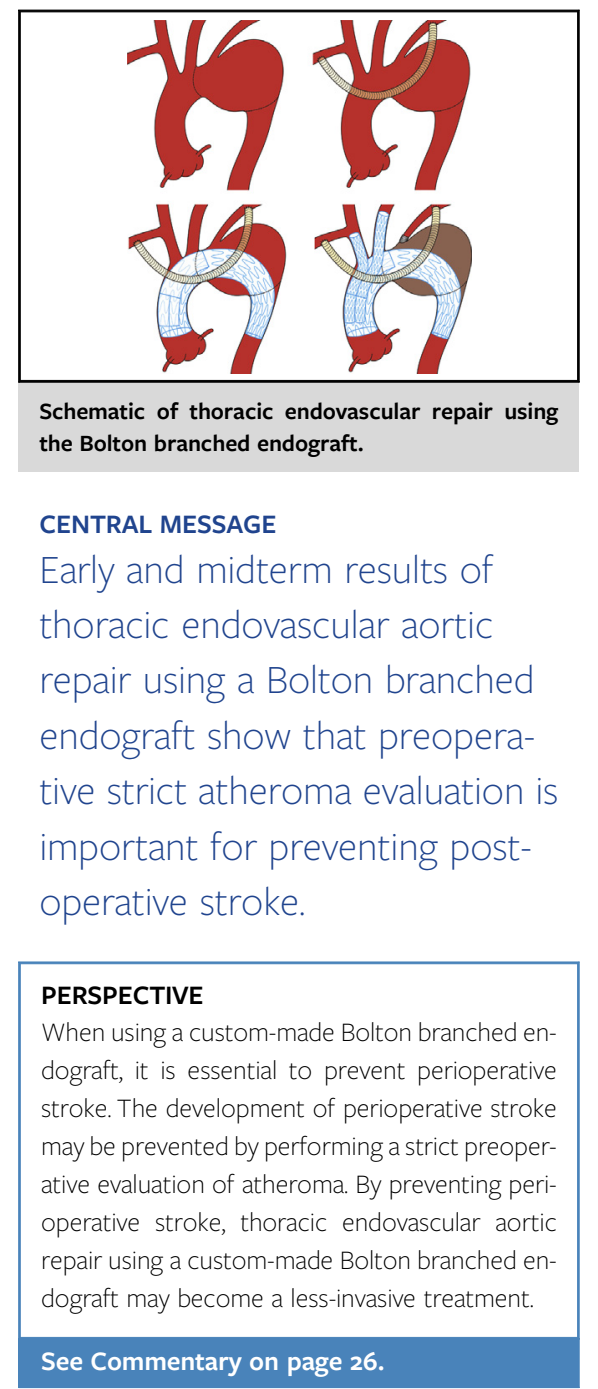

From the Departments of ${ }^{\mathrm{a} C}$ ardiovascular Surgery and ${ }^{\mathrm{b}}$ Minimally Invasive Cardiovascular Medicine, Osaka University Graduate School of Medicine, Suita, Osaka, Japan.

Received for publication Sept 18, 2020; accepted for publication Sept 21, 2020; available ahead of print Sept 26, 2020.

Address for reprints: Tomoaki Kudo, MD, PhD, and Yoshiki Sawa, MD, PhD, Department of Cardiovascular Surgery, Osaka University Graduate School of Medicine,
2-2, Yamadaoka, Suita, Osaka, 565-0871 Japan (E-mail: kudou-ygc@umin.ac.jp or sawa-p@surg1.med.osaka-u.ac.jp).

2666-2507

Copyright $(C) 2020$ The Authors. Published by Elsevier Inc. on behalf of The American Association for Thoracic Surgery. This is an open access article under the CC BY-NCND license (http://creativecommons.org/licenses/by-nc-nd/4.0/). https://doi.org/10.1016/j.xjtc.2020.09.023 


Abbreviations and Acronyms
3D $=3$-dimensional
AxA $=$ axillary artery
BCA $=$ brachiocephalic artery
CCA $=$ common carotid artery
LZ $=$ landing zone
MDCT $=$ multidetector computed tomography
TEVAR $=$ thoracic endovascular aortic repair

Video clip is available online.

Aortic arch pathologies are extremely difficult to treat because they require conventional open surgeries, which are highly invasive and complex procedures. ${ }^{1-3}$ Recently, hybrid thoracic endovascular aortic repair (TEVAR) gained increasing attention for the treatment of aortic arch pathologies. Hybrid TEVAR is preferred, especially in high-risk patients. However, aortocervical bypasses have to be created during zone 0 landing hybrid TEVAR, which include some moderately invasive surgical procedures. ${ }^{1,4,5}$ To reduce the invasiveness, we performed TEVAR using a branched stent-graft, in which complex aortocervical bypass or graft replacement is not required. Therefore, this study aims to elucidate the effectiveness of performing TEVAR using a Bolton branched endograft (Bolton Medical, Inc, Sunrise, Fla).

\section{PATIENTS AND METHODS Ethics Statement}

All protocols of the procedures in this study were approved by the Medical Ethics Committee of Osaka University School of Medicine (No. 15087). After fully explaining the surgical procedures and risks and presenting the results of the multidisciplinary team discussion to the patient, we obtained informed consent from the patient to undergo this procedure.

\section{Patients}

From October 2012 to June 2018, 368 patients underwent aortic repair for the treatment of aortic arch pathologies at Osaka University Hospital. Twenty-eight patients who were characterized as high risk for median sternotomy and aortocervical bypasses by several cardiovascular surgeons and cardiologists underwent TEVAR using a Bolton branched endograft.

\section{Preoperative Measurements}

All patients underwent contrast-enhanced multidetector computed tomography (MDCT) with 3-dimensional (3D) reconstruction by using an image-processing workstation (Aquarius Intuition, TeraRecon, Durham, NC) preoperatively to evaluate the adequacy of the proximal and distal landing zones (LZ); aortic arch, including the cervical arteries; and access route. MDCT images were acquired with a $\leq 1 \mathrm{~mm}$ slice thickness. We routinely followed-up with MDCT a week before discharge, at 6 months postoperatively, and yearly thereafter. The data were reviewed by cardiovascular surgeons who were blinded to this study.

\section{Device and Treatment Strategy}

An overview of the Bolton branched endograft is shown in Figure 1. The custom-made branched endograft is fundamentally similar to the Relay NBS graft (Bolton Medical, Inc). This device has a large gate (Figure 1, $A)$ to cannulate the cervical devices, with 1 or 2 internal inner tunnels (Figure 1,B). For cervical arteries, we used the Bolton cervical stent (Bolton Medical, Inc), the Gore Excluder contralateral leg (WL Gore \& Associates, Inc, Newark, Del), and the AAA iliac leg (Cook Zenith; Cook, Inc, Bloomington, Ind) (Figure 1,C). To prevent intraoperative stroke, we used the following filter devices: the Parachute (Tri-Med Corp, Osaka, Japan) and the Filtrap (Nipro Corp, Osaka, Japan).

We ensured the following preprocedural conditions regarding the treatment strategy: proximal LZ diameter $\leq 42 \mathrm{~mm}$, proximal LZ length $\geq 30 \mathrm{~mm}$, the length from the proximal LZ to the left common carotid artery (CCA) $\geq 95 \mathrm{~mm}$, and the proximal $\mathrm{LZ}$ and the cervical arteries of atheroma grade was 1 or 2 .

\section{Surgical Procedure}

The procedural steps are shown in Figure 1, $D$, and Video 1. Under general anesthesia, the patients received an extra-anatomical bypass from the right axillary artery (AxA) to the left AxA or from the right AxA to the left $\mathrm{CCA}$ and the left AxA using a ringed 8-mm expanded polytetrafluoroethylene graft (Figure 1,E). The balloon catheter was then inflated at the orifice of the left subclavian artery to protect against emboli after the bypass.

A pacemaker catheter was inserted for rapid pacing. The rapid pacing (heart rate $>160 \mathrm{bpm}$ ) was undergone while deploying the main branched graft. A straight wire was used to cross the aortic valve and advanced to the left ventricle. This was then exchanged for a curved superstiff wire. DynaCT was performed for 3D mapping. The main device was inserted through the femoral artery approach after inserting a pigtail catheter into the ascending aorta. After delivering the device to the descending aorta, the flexible inner sheath was advanced to the aortic arch and then toward the ascending aorta. We confirmed the precise match between the orifices of the cervical arteries and the device gate by performing standard angiography and 3D mapping. Rapid pacing was started, and the main body of the device was deployed at a constant speed (Figure 1,F).

Next, the wire was advanced to the posterior tunnel from the right CCA, and the measurement catheter was advanced to this tunnel to select the cervical device. The stent-graft for the brachiocephalic artery (BCA) was inserted into the tunnel and deployed carefully followed by touch-up ballooning. Stent-graft deployment in the left CCA was performed using the same procedure for the double-side branched stent-graft (Figure 1, G). Lastly, we performed coiling of the left subclavian artery using the balloon catheter, which was inserted before deploying the stent-grafts. Aortography was conducted to check for endoleaks and bypass patency.

\section{Follow-up}

Follow-up included regular clinical visits at least once every 3 months for the first postoperative year and then once every 6 months or at 1 year thereafter in our hospital. We recorded the confirmed death of the patients through telephone interviews with their families.

The data of aortic events, including known/suspected events, such as stroke, aneurysm enlargement $\geq 5 \mathrm{~mm}$ in diameter, or any cases of endoleak, stent-graft migration, aortic rupture, aortic dissection, and prosthetic infection were recorded. Aorta-related death was defined as death due to adverse events secondary to aortic pathologies.

\section{Statistical Analyses}

Results are expressed as mean \pm standard deviation and median (interquartile range [IQR]) according to the normality of the distribution, as 

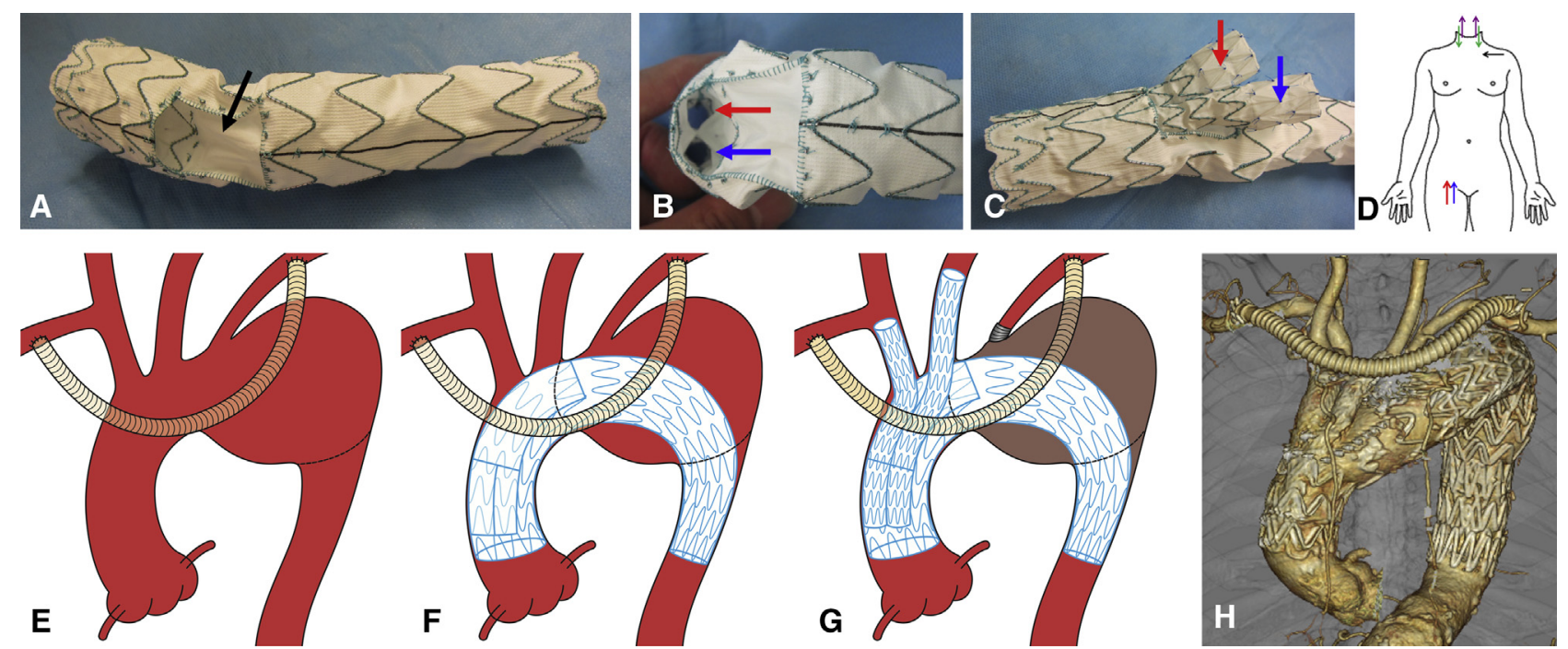

FIGURE 1. Overview of the Bolton branched endograft (Bolton Medical, Inc, Sunrise, Fla) and schema of the surgical procedure of the Bolton branched endograft. A, Main body of the Bolton branched endograft with a large gate (black arrow). B, Inner tunnels (brachiocephalic artery [BCA]: red arrow, left common carotid artery [CCA]: blue arrow). C, Overview of the Bolton branched endograft (BCA: red arrow, left CCA: blue arrow). D, Overview of the approach site: Bolton branched endograft from the common femoral artery (red arrow), pacemaker catheter from the right common femoral vein (blue arrow), cervical devices from the CCAs (green arrow), filter devices for protecting against emboli from the CCA (purple arrow), and balloon catheter for protecting against emboli from the left axillary artery (AxA) (black arrow). E, Extra-anatomical bypass from the right AxA to the left CCA using a ringed 8-mm expanded polytetrafluoroethylene graft. F, The Bolton branched endograft is deployed under rapid pacing (heart rate $>160 \mathrm{bpm}$ ) after confirming the precise match between the orifices of the cervical arteries and the device gate by standard angiography and 3-dimensional (3D) mapping. G, The stent grafts for the cervical arteries are inserted in the tunnels and deployed. H, 3D computed tomography image after the procedure.

assessed with the Shapiro-Wilk test. Categorical variables are presented as counts and percentages. The curves for overall survival and freedom from aorta-related death and aortic events were estimated using the KaplanMeier product-limiting method. All statistical analyses were performed using JMP statistical software, version 14.0.0 for MacOS X (SAS Institute Inc, Cary, NC).

\section{RESULTS}

\section{Patient Characteristics}

The patient characteristics are listed in Table 1. The follow-up period was $4.0 \pm 2.0$ years (IQR, 0.5-7.0 years), and all $28(100 \%)$ patients completed the study. The age of the whole cohort was $78.4 \pm 6.9$ years (IQR, 66-87 years), $15(53.6 \%)$ patients were older than age 80 years, and 17 $(60.7 \%)$ patients were men. All patients underwent the elective procedure. The pathologies consisted of degenerative aneurysm in $22(78.6 \%)$ patients and dissecting aortic aneurysm in $6(21.4 \%)$ patients. Of 28 patients, $14(50.0 \%)$ had a history of previous cardiovascular surgery. Five $(17.9 \%)$ patients had previous median sternotomy, and 7 $(25.0 \%)$ had undergone endovascular aortic repair (TEVAR or endovascular aortic repair). The median logistic European System for Cardiac Operative Risk Evaluation and European System for Cardiac Operative Risk Evaluation 2 were $38.8 \%$ (IQR, 33.1\%-46.0\%) and $6.6 \%$ (IQR, $5.7 \%-8.9 \%$ ), respectively.
Preoperative measurements using MDCT are summarized in Table 1 . The median maximum aneurysm diameter was $56.5 \mathrm{~mm}$ (IQR, 54.3-60.8 $\mathrm{mm}$ ). The mean diameter of the proximal and distal LZ, and the mean length of the lesser proximal LZ were $34.3 \pm 3.6 \mathrm{~mm}, 29.1 \pm 3.4 \mathrm{~mm}$, and $34.6 \pm 8.5 \mathrm{~mm}$, respectively. Atheroma grade $\geq 2$ was detected in the ascending aorta ( 9 out of 28 [32.1\%]), BCA (6 out of 28 [21.4\%]), and left CCA (4 out of 28 [14.3\%]).

\section{Procedure Outcomes}

The postoperative data are listed in Table 2. All procedures were successful; no endoleaks occurred, conversion to open repair during the 30 postoperative days did not occur. The mean \pm standard deviation operative time, including cervical bypassing, was $229 \pm 48$ minutes (IQR, 150-356 minutes). Twenty-five (89.3\%) patients were extubated in the operating room. Double-side and single-side branched devices were used in $24(85.7 \%)$ and $4(14.3 \%)$ patients, respectively. For BCA, the Bolton cervical stent was used in $9(32.1 \%)$ patients, Gore Excluder iliac leg in 17 (60.7\%), and the Cook Zenith AAA iliac leg in $2(7.1 \%)$. For the left CCA, we used the Bolton cervical stent in $7(29.2 \%)$ patients, the Gore Excluder contralateral leg in $13(54.2 \%)$, and the Cook Zenith AAA iliac leg in $2(8.3 \%)$. 


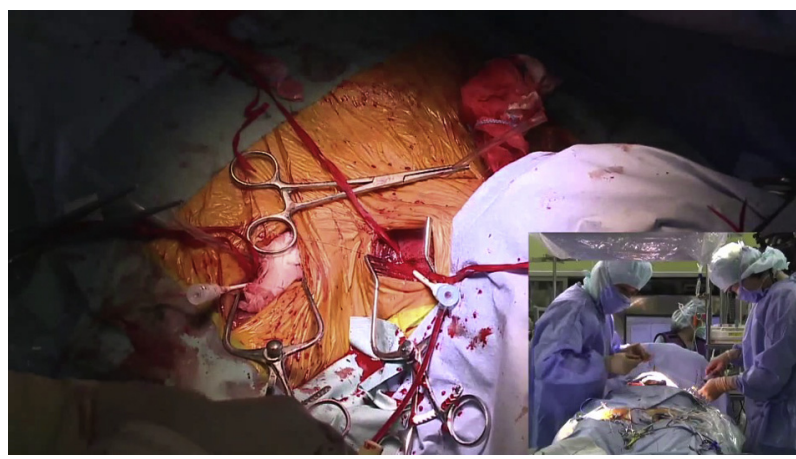

VIDEO 1. Overview of the Bolton branched endograft. The custom-made branched device is fundamentally similar to the Relay NBS device (Bolton Medical, Inc, Sunrise, Fla). This device has a large gate to cannulate the cervical devices easily, with 2 internal inner tunnels. Case: A 67-year-old man underwent the graft replacement of the ascending aorta due to type A dissection in 2004. A large entry exists at the distal side of the graft anastomosis and the false lumen has enlarged to $62 \mathrm{~mm}$. We planned to perform total endovascular repair using the Bolton double-side branch system (Bolton Medical, Inc); the proximal and distal sizes are $36 \mathrm{~mm}$ and $26 \mathrm{~mm}$, respectively. Procedure: Under general anesthesia, the patient receives an extra-anatomical bypass from the right axillary artery (AxA) to the left AxA or from the right AxA to the left common carotid artery (CCA) and the left AxA using a ringed 8-mm expanded polytetrafluoroethylene graft. The balloon catheter is then inflated at the orifice of the left subclavian artery to protect against emboli after the bypass. A pacemaker catheter is inserted for rapid-pacing. The rapid pacing is undergone while deploying the main branched graft. A straight wire is used to cross the aortic valve and advanced to the left ventricle. This was then exchanged for a curved superstiff wire. Dyna-computed tomography is performed for 3-dimensional (3D) mapping. The main device is inserted through the right femoral artery approach. After delivering the device to the descending aorta, the flexible inner sheath is advanced to the aortic arch and then toward the ascending aorta. We confirm the precise match between the orifices of the cervical arteries and the device gate by performing standard angiography and 3D mapping. Rapid pacing (heart rate $180 \mathrm{bpm}$ ) is started, and the main body of the device is deployed at a constant speed. Next, the wire is advanced to the posterior tunnel from the right CCA, and the measurement catheter is advanced to this tunnel to select the cervical device. The stentgraft device for the brachiocephalic artery is inserted into the tunnel and deployed carefully, and touch-up ballooning is performed. For the left CCA, the same deployment procedure is performed for the double-side branched stent-graft. Lastly, we perform coiling of the left subclavian artery using the balloon catheter, which is inserted before deploying the stent-grafts. Aortography is conducted to check for endoleaks and bypass patency. Video available at: https://www.jtcvs.org/article/S2666-2507(20) 30542-3/fulltext.

In 3 cases $(10.7 \%)$, an additional stent-graft was used at the distal LZ; in 10 cases $(35.7 \%)$, the filter devices were used in the cervical arteries to prevent intraoperative stroke. One patient (3.6\%) had left ventricle rupture caused by the stiff wire. The median size and mean oversizing rate of the proximal stent-graft were $41.0 \mathrm{~mm}$ (IQR, 38.0-46.0 mm) and $120 \% \pm 8 \%$, respectively.
TABLE 1. Patient characteristics and preoperative measurement $(\mathbf{N}=\mathbf{2 8})$

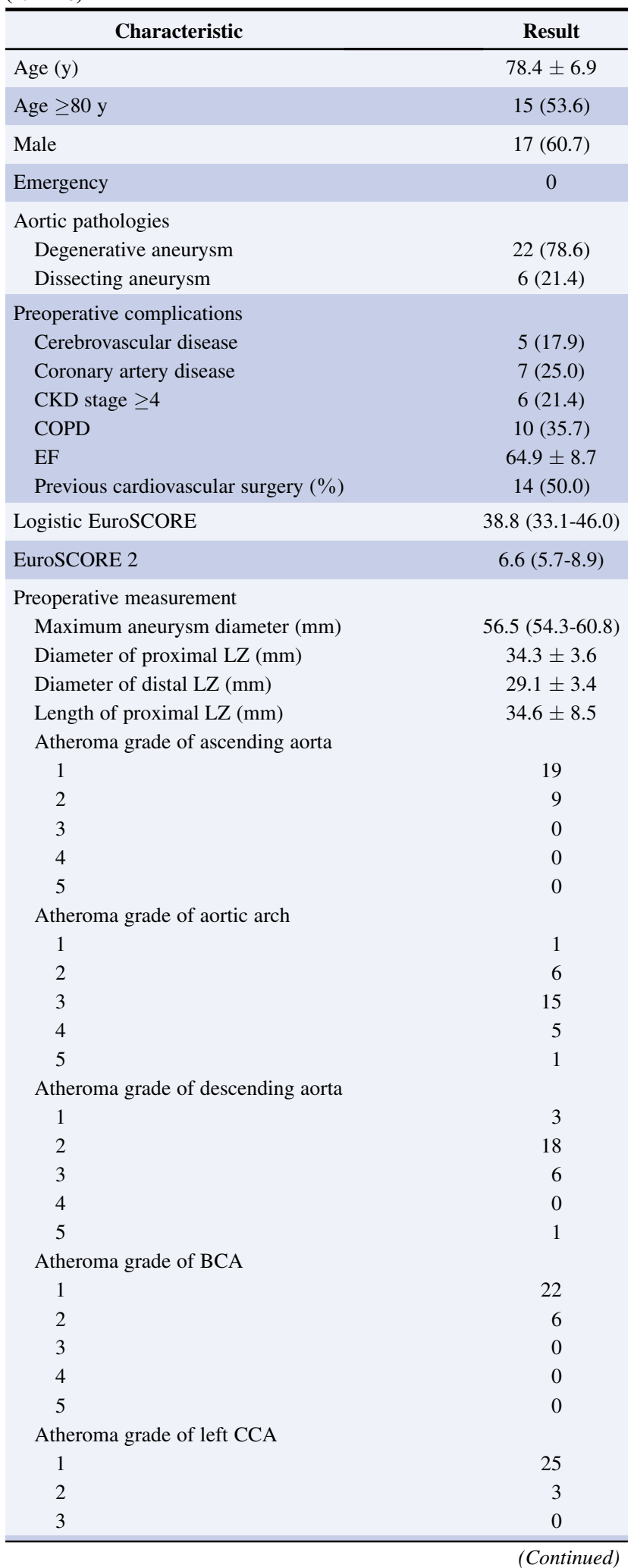


TABLE 1. Continued

\begin{tabular}{ccc}
\hline & Characteristic & Result \\
\hline 4 & 0 \\
5 & 0
\end{tabular}

Values are presented as mean \pm standard deviation, $\mathrm{n}(\%)$, median (interquartile range), or n. $C K D$, Chronic kidney disease; $C O P D$, chronic obstructive pulmonary disease; $E F$, ejection fraction; EuorSCORE, European System for Cardiac Operative Risk Evaluation; $L Z$, landing zone; $B C A$, brachiocephalic artery; $C C A$, common carotid artery.

TABLE 2. Procedure and stent-graft $(\mathrm{N}=28)$

\begin{tabular}{|c|c|}
\hline Variable & Result \\
\hline Procedure success & $28(100)$ \\
\hline Operative time (min) & $229 \pm 48$ \\
\hline Extubation in operating room & $25(89.3)$ \\
\hline 30-d mortality & 0 \\
\hline In-hospital mortality ( $\%)$ & 0 \\
\hline \multicolumn{2}{|l|}{ Procedure } \\
\hline $\begin{array}{l}\text { Double-side branched device and } \\
\text { right AxA-left AxA bypass }\end{array}$ & $24(85.7)$ \\
\hline $\begin{array}{l}\text { Single-side branched device and } \\
\text { right AxA-left CCA-left AxA bypass }\end{array}$ & $3(10.7)$ \\
\hline $\begin{array}{l}\text { Single-side branched device and } \\
\text { right AxA-left CCA bypass }\end{array}$ & $1(3.6)$ \\
\hline \multicolumn{2}{|l|}{ Main stent-grafts } \\
\hline Size of proximal stent-graft (mm) & $41.0(38.0-46.0)$ \\
\hline Size of distal stent-graft (mm) & $35.0(30.0-38.0)$ \\
\hline Proximal stent-graft oversizing rate & $120 \pm 8$ \\
\hline Distal stent-graft oversizing rate & $117 \pm 9$ \\
\hline BCA stent-grafts & $28(100)$ \\
\hline Bolton* cervical stent & $9(32.1)$ \\
\hline Gore $\nmid$ Excluder contralateral leg & $17(60.7)$ \\
\hline Cook Zenith + AAA iliac leg & $2(7.1)$ \\
\hline Left CCA stent-grafts & $24(85.7)$ \\
\hline Bolton* cervical stent & $7(29.2)$ \\
\hline Gore $\nmid$ Excluder contralateral leg & $13(54.2)$ \\
\hline Cook Zenith $\ddagger$ AAA iliac leg & $2(8.3)$ \\
\hline \multicolumn{2}{|l|}{ Additional procedures } \\
\hline Distal TEVAR & $3(10.7)$ \\
\hline Filter protection of cervical arteries & $10(35.7)$ \\
\hline \multicolumn{2}{|l|}{ Intraoperative incidents } \\
\hline Massive bleeding & 0 \\
\hline LV rupture & $1(3.6)$ \\
\hline Retrograde type A dissection & 0 \\
\hline Any other dissection & 0 \\
\hline
\end{tabular}

Values are presented as $\mathrm{n}(\%)$, mean \pm standard deviation, or median (interquartile range). AxA, Axillary artery; $C C A$, common carotid artery; TEVAR, thoracic endovascular aortic repair; $L V$, left ventricular. *Bolton Medical, Inc, Sunrise, Fla. †W.L. Gore \& Associates, Newark, Del. †Cook, Inc, Bloomington, Ind.
TABLE 3. Thirty-day and midterm outcomes $(\mathrm{N}=28)$

\begin{tabular}{|c|c|}
\hline Outcome & Result \\
\hline \multicolumn{2}{|l|}{ 30-d complications } \\
\hline Stroke & $4(14.3)$ \\
\hline Transient neurologic dysfunction & $2(7.1)$ \\
\hline Disabling stroke & $2(7.1)$ \\
\hline Spinal cord injury & 0 \\
\hline Cardiac events & 0 \\
\hline Tracheostomy & $1(3.6)$ \\
\hline Bowel ischemia & 0 \\
\hline \multicolumn{2}{|l|}{ 30-d aortic events } \\
\hline Retrograde type A dissection & 0 \\
\hline Aneurysm rupture & 0 \\
\hline Stent-graft migration & 0 \\
\hline Stent-graft-induced distal re-dissection & 0 \\
\hline Stent-graft infection & 0 \\
\hline Bypass graft occlusion & 0 \\
\hline \multicolumn{2}{|l|}{ 30-d endoleak } \\
\hline Type 1a & 0 \\
\hline Type $1 b$ & 0 \\
\hline Type 2 & 0 \\
\hline Type 3 & 0 \\
\hline \multicolumn{2}{|l|}{ Midterm complications } \\
\hline Stroke & 0 \\
\hline Spinal cord injury & 0 \\
\hline Cardiac events & 0 \\
\hline Bowel ischemia & 0 \\
\hline \multicolumn{2}{|l|}{ Midterm aortic events } \\
\hline Retrograde type A dissection & 0 \\
\hline Aneurysm rupture & $2(7.1)$ \\
\hline Stent-graft migration & $2(7.1)$ \\
\hline Stent-graft-induced distal re-dissection & 0 \\
\hline Stent-graft infection & 0 \\
\hline Bypass graft occlusion & 0 \\
\hline \multicolumn{2}{|l|}{ Midterm endoleak } \\
\hline Type 1a & 0 \\
\hline Type $1 b$ & $1(3.6)$ \\
\hline Type 2 & 0 \\
\hline Type 3 & $1(3.6)$ \\
\hline \multicolumn{2}{|l|}{ Aneurysm change } \\
\hline Enlarge & $2(7.1)$ \\
\hline No change & $25(89.3)$ \\
\hline Shrinkage & $1(3.6)$ \\
\hline Disappear & 0 \\
\hline
\end{tabular}

\section{Thirty-Day Outcomes}

We did not note 30-day mortality or in-hospital mortality. Four $(14.3 \%)$ patients developed symptomatic stroke. Two (7.1\%) patients developed transient neurologic dysfunction as they recovered from cerebral infarction. Two $(7.1 \%)$ patients had disabling stroke (modified Rankin scale $\geq 2$ ). In 


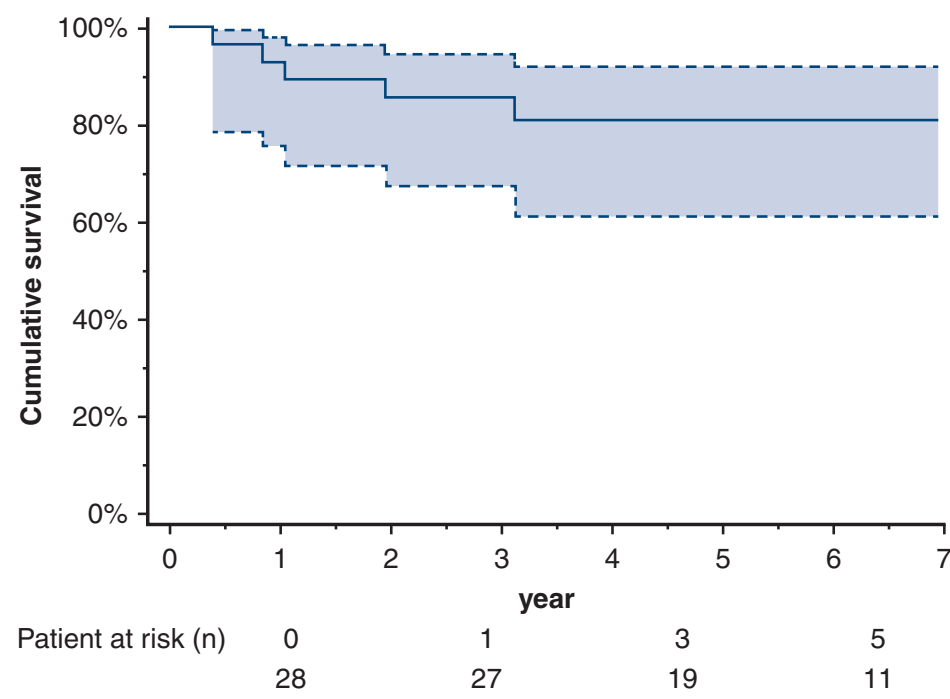

A

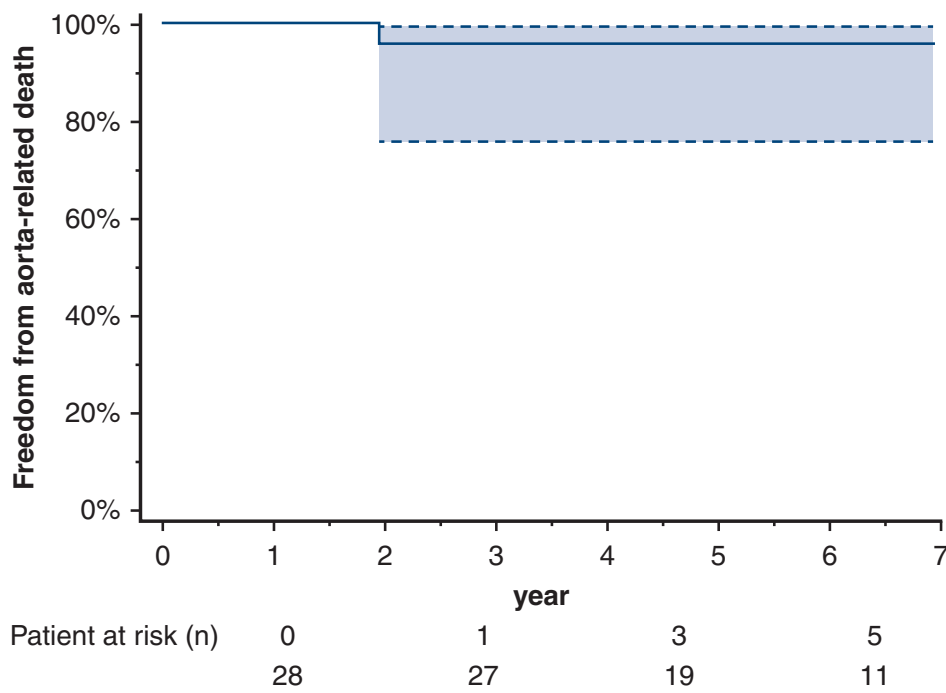

B

FIGURE 2. Kaplan-Meier curves. A, Cumulative survival. The cumulative survival rates at 1,3 , and 5 years are $92.7 \%, 85.6 \%$, and $80.8 \%$, respectively. B, Freedom from aorta-related death. The aorta-related death-free rates at 1, 3, and 5 years are $100 \%, 95.8 \%$, and $95.8 \%$, respectively. C, Freedom from aortic events. The aortic event-free survival rates at 1,3 , and 5 years are $85.7 \%, 81.6 \%$, and $81.6 \%$, respectively.

contrast, spinal cord injury and bowel ischemia due to emboli were not detected. One patient developed laryngeal edema after 1 week postoperatively requiring tracheotomy. No incidence of migration, collapse, or endoleak as stentgraft associated complications was reported (Table 3).

\section{Midterm Outcomes}

The cumulative survival rates at 1,3 , and 5 years were $92.7 \%, 85.6 \%$, and $80.8 \%$, respectively (Figure 2, $A$ ). There were 5 deaths during the follow-up period, including $1(3.6 \%)$ patient who developed aneurysmal rupture postoperatively due to a type $1 \mathrm{~b}$ endoleak at 1.5 years and then died 1.9 years later. The other 4 postoperative deaths were caused by cancer ( 1 case, at 3.1 years) and pneumonia ( 3 cases, at $0.4,0.8$, and 1.1 years, respectively). The aortarelated death-free rate at 5 years was $95.8 \%$ (Figure 2, B).

The aortic event-free survival rates at 1,3 , and 5 years were $85.7 \%, 81.6 \%$, and $81.6 \%$, respectively (Figure 2, $C)$. During the follow-up period, there were 6 aortic events. Four $(14.3 \%)$ patients had perioperative stroke and 2 (7.1\%) patients had aneurysmal rupture due to type $1 \mathrm{~b}$ endoleak at 1.5 years and type 3 endoleak at 5.8 years. They underwent additional TEVAR. Of these 2 patients, 1 patient with type 3 endoleak survived, whereas the other did not. 


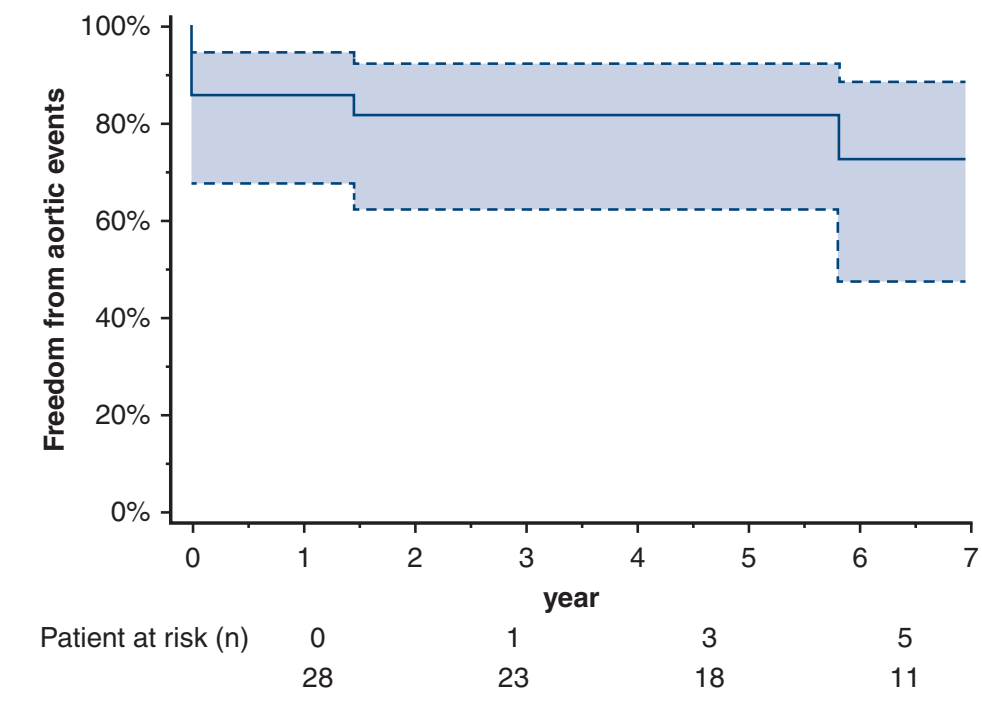

C

FIGURE 2. (Continued).

Cases of retrograde type A dissection, type 1a endoleak, other aortic events, or midterm complications, such as stroke, were not reported (Table 3).

Aneurysm changes are listed in Table 3. In most cases (25 out of $28[89.3 \%]$ ), there was no change in the aneurysmal diameter. Two patients $(7.1 \%)$ with aneurysmal enlargement had endoleaks due to type $1 \mathrm{~b}$ and type 3 endoleaks.

\section{Stroke}

The detailed characteristics of 4 (4 out of 28 [14.3\%]) patients with perioperative stroke are listed in Table 4. Of the 4 patients, 2 (2 out of 28 [7.1\%]) patients had disabling stroke. The numbers of patients with atheroma grade $\geq 2$ in the BCA and left CCA were 6 (6 out of 28 [21.4\%]) and 4 (4 out of $28[14.2 \%]$ ), respectively. Of these patients, $66.7 \%$ ( 4 out of 6 ) patients with atheroma grade $\geq 2$ in the BCA and $25.0 \%$ ( 1 out of 4 ) patients with atheroma grade $\geq 2$ in the left CCA had perioperative stroke. Filter devices of cervical arteries were used in 10 (10 out of 28 [35.7\%]) patients. Of those, 2 (2 out of 10 [20.0\%]) patients had disabling stroke (Table 5).

\section{DISCUSSION}

Zone 0 landing hybrid TEVAR without cardiopulmonary bypass for the aortic arch pathologies is less invasive than conventional open arch repair. ${ }^{6,7}$ However, this procedure is still relatively invasive because median sternotomy and multiple cervical arterial bypasses are performed. In addition, the mortality rates of zone 0 landing TEVAR were $5 \%$ to $12 \%$ in previous studies, which is considered high. ${ }^{1,4,8-13}$

The fenestrated and the chimney graft technique were prevalently used for their minimal invasiveness and have substituted for the hybrid TEVAR procedure. The fenestrated devices are perforated in the cervical branch of the stent-graft that helps sustain blood flow to those areas. However, there are possible concerns of endoleaks from fenestrations after surgery and uncertain long-term outcomes. ${ }^{14-17}$ Regarding the chimney graft technique, the overlap between the 2 devices in the proximal LZ creates a gutter between the stent-grafts, leading to a type 1a endoleak occasionally, which can prevent the completion of aortic treatment. ${ }^{18-23}$

TABLE 4. Characteristics of 4 patients with stroke

\begin{tabular}{|c|c|c|c|c|c|c|c|c|c|c|c|c|}
\hline \multirow[b]{2}{*}{ Case } & \multirow[b]{2}{*}{ Stroke } & \multirow[b]{2}{*}{ Age } & \multirow[b]{2}{*}{ Pathology } & \multicolumn{5}{|c|}{ Atheroma grade } & \multicolumn{3}{|c|}{ Device } & \multirow[b]{2}{*}{ Filter } \\
\hline & & & & Asc Ao & Arch & Dec Ao & BCA & Left CCA & Main & BCA & Left CCA & \\
\hline 1 & Transient & 75 & Degenerative & 1 & 2 & 2 & 2 & 1 & DS & B & $\mathrm{B}$ & No \\
\hline 2 & Transient & 66 & Degenerative & 1 & 2 & 3 & 2 & 1 & DS & B & B & No \\
\hline 3 & Disabling & 84 & Degenerative & 1 & 4 & 2 & 2 & 1 & DS & B & B & Yes \\
\hline 4 & Disabling & 73 & Degenerative & 2 & 3 & 2 & 2 & 2 & SS & G & - & Yes \\
\hline
\end{tabular}

$A s c A o$, Ascending aorta; $D e c A o$, descending aorta; $B C A$, brachiocephalic artery; $C C A$, common carotid artery; $D S$, double-side branched device; $B$, Bolton (Bolton Medical, Inc, Sunrise, Fla) abdominal stent; $S S$, single-side branched device; $G$, Gore Excluder (W.L. Gore \& Associates, Newark, Del) contralateral leg. 
TABLE 5. Stroke

\begin{tabular}{lrrc}
\hline \multicolumn{1}{c}{ Characteristic } & N & Stroke & Stroke \\
\hline Preoperative characteristic & & & \\
Age $\geq 80$ y & 15 & 1 & $1 / 15(6.7)$ \\
Gender: Male & 17 & 2 & $2 / 17(11.8)$ \\
Aortic pathologies: Degenerative & 23 & 4 & $4 / 23(17.4)$ \\
Cerebrovascular disease & 7 & 2 & $2 / 7(28.6)$ \\
Atheroma grade & & & \\
Ascending aorta $\geq 2$ & 9 & 1 & $1 / 9(11.1)$ \\
Aortic arch $\geq 3$ & 21 & 2 & $2 / 21(9.5)$ \\
Descending aorta $\geq 3$ & 7 & 1 & $1 / 7(14.3)$ \\
BCA $\geq 2$ & 6 & 4 & $4 / 6(66.7)$ \\
Left CCA $\geq 2$ & 4 & 1 & $1 / 4(25.0)$ \\
Device & & & \\
Main: Double-side branched device & 24 & 3 & $3 / 24(12.5)$ \\
Stent-graft of BCA: Bolton* cervical stent & 9 & 3 & $3 / 9(33.3)$ \\
Stent-graft of left CCA: Bolton* & 7 & 2 & $2 / 7(28.6)$ \\
$\quad$ cervical stent & & & \\
Filter protection & 10 & 2 & $2 / 10(20.0)$ \\
\hline
\end{tabular}

Values are presented as $\mathrm{n}$ or $\mathrm{n} / \mathrm{n}(\%) . B C A$, Brachiocephalic artery; $C C A$, common carotid artery. *Bolton Medical, Inc, Sunrise, Fla.

Therefore, device manufacturers developed branched devices for clinical applicability. Branched graft devices for aortic arch diseases, including custom-made devices have gained recent attention. ${ }^{24-29}$ In this study, we used a Bolton branched endograft that has a large gate, which significantly facilitates the cannulation of cervical devices into the inner tunnel within the main device. This study did not detect 30-day mortality and in-hospital deaths, which were reported by some other studies..$^{30-33}$

In this study, our midterm results were satisfactory because there were no cases of retrograde type A dissection, type 1a endoleak, and the aorta-related death-free rate at 5 years was $95.8 \%$. However, the postoperative stroke rate reported in our study was $14 \%$ (4 out of 28 ), which was higher than that reported in previous studies $(5 \%$ to $11.4 \%$ ) with zone 0 landing TEVAR. This outcome is not better than the results of previous studies on zone 0 landing TEVAR, and it is not an acceptable result with regard to cerebral infarction. ${ }^{4,8,9}$ We selected the patients who did not have a shaggy ascending aorta and BCA. Regarding the ascending aorta, our results show that the thrombus in the ascending aorta did not cause any significant difference in stroke. However, all patients with stroke had an atheroma grade $\geq 2$ in the BCA. Cerebral infarction could have been caused by a stent-graft making contact with the atheroma during insertion of the cervical stent-graft and deployment of the stent-graft, resulting in atheroma embolism. For postoperative stroke prevention, the results of this study showed how important it is to conduct preoperative strict atheroma evaluation of the cervical arteries, especially. Study patients with atheroma grade $\geq 2$ in the BCA may develop cerebral infarction after this procedure; therefore, at this time, we suggest that it is better to not perform TEVAR for these patients. Instead, graft replacement of the ascending aorta and cervical arteries should be performed using circulatory arrest and cardiopulmonary bypass to reduce the incidence of stroke. However, for patients who cannot tolerate such invasive surgery, minimally invasive surgery such as branched TEVAR is essential. Therefore, the development of a novel filter device for cervical arteries is imperative to prevent the cerebral infarction.

Concerning the use of this branched endograft device, it is imperative to carefully select patients without aortic thrombi, including the cervical arteries. Therefore, targeting aortic dissections in having cleaner aortic wall areas is advisable. In particular, the residual aortic dissection after ascending aortic graft replacement for acute type A aortic dissection may best indicate the need for TEVAR using a branched endograft. ${ }^{34}$ In this study, no strokes occurred with TEVAR using a branched endograft for residual dissection. Additionally, the use of the filter device was not effective in this study. However, we assume that the use of the filter device might have prevented a cerebral infarction event according to the study by Shimamura and colleagues. ${ }^{35}$ Hence, improvement of the filter device for the cervical arteries may prevent cerebral infarction.

\section{Limitations}

This study is the retrospective study and has a relatively small study size. Our study period also was limited because it did not include a long-term follow-up period. Therefore, a prospective multicenter study with a long-term follow-up is required to confirm our findings. Moreover, the findings of this study need to be validated by further clinical investigations.

\section{CONCLUSIONS}

We achieved satisfactory early and midterm results of performing TEVAR using the Bolton branched endograft, which did not require complex aortocervical bypass or graft replacement procedures. This study demonstrated the importance of conducting preoperative strict atheroma evaluation to prevent postoperative stroke, which is the most serious complication. Although long-term results, a larger study size, and strict evaluation of preoperative atheroma to prevent postoperative stroke are needed, TEVAR using the Bolton branched endograft may be considered among the less-invasive treatments for aortic arch pathologies.

\section{Conflict of Interest Statement}

The authors reported no conflicts of interest.

The Journal policy requires editors and reviewers to disclose conflicts of interest and to decline handling or reviewing manuscripts for which they may have a conflict 
of interest. The editors and reviewers of this article have no conflicts of interest.

\section{References}

1. Preventza O, Garcia A, Cooley DA, Haywood-Watson RJ, Simpson K, Bakaeen FG, et al. Total aortic arch replacement: a comparative study of zone 0 hybrid arch exclusion versus traditional open repair. J Thorac Cardiovasc Surg. 2015;150:1591-8.

2. Sundt TM III, Orszulak TA, Cook DJ, Schaff HV. Improving results of open arch replacement. Ann Thorac Surg. 2008;86:787-96.

3. Misfeld M, Leontyev S, Borger MA, Gindensperger O, Lehmann S, Legare JF, et al. What is the best strategy for brain protection in patients undergoing aortic arch surgery? A single center experience of 636 patients. Ann Thorac Surg. 2012; 93:1502-8.

4. Aalaei-Andabili SH, Scali S, Klodell C, Lee T, Hess P, Martin T, et al. Outcomes of antegrade stent graft deployment during hybrid aortic arch repair. Ann Thorac Surg. 2017; 104:538-44

5. Andersen ND, Williams JB, Hanna JM, Shah AA, McCann RL, Hughes GC. Results with an algorithmic approach to hybrid repair of the aortic arch. J Vasc Surg. 2013:57:655-67.

6. Milewski RK, Szeto WY, Pochettino A, Moser GW, Moeller P, Bavaria JE. Have hybrid procedures replaced open aortic arch reconstruction in high-risk patients? A comparative study of elective open arch debranching with endovascular stent graft placement and conventional elective open total and distal aortic arch reconstruction. J Thorac Cardiovasc Surg. 2010;140:590-7.

7. De Rango P, Ferrer C, Coscarella C, Musumeci F, Verzini F, Pogany G, et al. Contemporary comparison of aortic arch repair by endovascular and open surgical reconstructions. J Vasc Surg. 2015;61:339-46.

8. Narita H, Komori K, Usui A, Yamamoto K, Banno H, Kodama A, et al. Postoperative outcomes of hybrid repair in the treatment of aortic arch aneurysms. Ann Vasc Surg. 2016;34:55-61.

9. Kent WD, Appoo JJ, Bavaria JE, Herget EJ, Moeller P, Pochettino A, et al. Results of type II hybrid arch repair with zone 0 stent graft deployment for complex aortic arch pathology. J Thorac Cardiovasc Surg. 2014;148:2951-5.

10. Preventza O, Tan CW, Orozco-Sevilla V, Euhus CJ, Coselli JS. Zone zero hybrid arch exclusion versus open total arch replacement. Ann Cardiothorac Surg. 2018; 7:372-9.

11. Weigang E, Parker J, Czerny M, Peivandi AA, Dorweiler B, Beyersdorf F, et al. Endovascular aortic arch repair after aortic arch de-branching. Ann Thorac Surg. 2009;87:603-7.

12. Faure EM, Canaud L, Marty-Ane C, Alric P. Hybrid aortic arch repair for dissecting aneurysm. J Thorac Cardiovasc Surg. 2016;152:162-8.

13. Czerny M, Weigang E, Sodeck G, Schmidli J, Antona C, Gelpi G, et al. Targeting landing zone 0 by total arch rerouting and TEVAR: midterm results of a transcontinental registry. Ann Thorac Surg. 2012;94:84-9.

14. Azuma T, Yokoi Y, Yamazaki K. The next generation of fenestrated endografts: results of a clinical trial to support an expanded indication for aortic arch aneurysm treatment. Eur J Cardiothorac Surg. 2013;44:e156-63.

15. Kawaguchi S, Yokoi Y, Shimazaki T, Koide K, Matsumoto M, Shigematsu H. Thoracic endovascular aneurysm repair in Japan: experience with fenestrated stent grafts in the treatment of distal arch aneurysms. J Vasc Surg. 2008;48:24S-9S

16. Kurimoto Y, Maruyama R, Ujihira K, Nishioka N, Hasegawa K, Iba Y, et al. Thoracic endovascular aortic repair for challenging aortic arch diseases using fenestrated stent grafts from zone 0. Ann Thorac Surg. 2015;100:24-32.

17. Yokoi Y, Azuma T, Yamazaki K. Advantage of a precurved fenestrated endograft for aortic arch disease: simplified arch aneurysm treatment in Japan 2010 and 2011. J Thorac Cardiovasc Surg. 2013;145:S103-9.

18. Ahmad W, Buse C, Kroger JR, Mylonas S, Majd P, Brunkwall S, et al. A shorter aortic arch sealing ring $(<10 \mathrm{~mm})$ distal to the most distal chimney seems to be an additional important factor contributing to a gutter endoleak in aortic arch TEVAR. Ann Vasc Surg. 2019;61:116-23.

19. Bangard C, Franke M, Pfister R, Deppe AC, Matoussevitch V, Maintz D, et al Thoracic type Ia endoleak: direct percutaneous coil embolization of the aortic arch at the blood entry site after TEVAR and double-chimney stent-grafts. Eur Radiol. 2014:24:1430-4.

20. Derbel B, Tolenaar JL, Trimarchi S. Use of Chimney graft after accidental coverage of the left common carotid artery in TEVAR procedure. Tunis Med. 2014;92:756-9.

21. Moulakakis KG, Mylonas SN, Avgerinos E, Papapetrou A, Kakisis JD Brountzos EN, et al. The chimney graft technique for preserving visceral vessels during endovascular treatment of aortic pathologies. J Vasc Surg. 2012;55 1497-503.

22. Sindhvananda $W$, Leelachiewchankul F. Thoracic endovascular aortic repair with chimney technique (chimney TEVAR) for aortic arch pathologies: cardiovascular problems during anesthesia. J Med Assoc Thai. 2016;99:1328-36.

23. Wang L, Huang Y, Guo D, Xu X, Chen B, Jiang J, et al. Application of triplechimney technique using C-TAG and Viabahn or Excluder iliac extension in TEVAR treatment of aortic arch dilation diseases. J Thorac Dis. 2018;10: 3783-90.

24. Haulon S, Greenberg RK, Spear R, Eagleton M, Abraham C, Lioupis C, et al Global experience with an inner branched arch endograft. J Thorac Cardiovasc Surg. 2014;148:1709-16.

25. Tsilimparis N, Debus ES, von Kodolitsch Y, Wipper S, Rohlffs F, Detter C, et al Branched versus fenestrated endografts for endovascular repair of aortic arch lesions. J Vasc Surg. 2016;64:592-9.

26. Milne CP, Amako M, Spear R, Clough RE, Hertault A, Sobocinski J, et al. Innerbranched endografts for the treatment of aortic arch aneurysms after open ascending aortic replacement for type a dissection. Ann Thorac Surg. 2016 102:2028-35.

27. Patel HJ, Dake MD, Bavaria JE, Singh MJ, Filinger M, Fischbein MP, et al Branched endovascular therapy of the distal aortic arch: preliminary results of the feasibility multicenter trial of the gore thoracic branch endoprosthesis. Ann Thorac Surg. 2016;102:1190-8.

28. Hofmann M, Pecoraro F, Planer D, Pfammatter T, Puippe G, Bettex D, et al. Early outcomes with a single-sided access endovascular stent. J Vasc Surg. 2018;68: 83-90.e2.

29. van Bakel TM, de Beaufort HW, Trimarchi S, Marrocco-Trischitta MM, Bismuth J, Moll FL, et al. Status of branched endovascular aortic arch repair. Ann Cardiothorac Surg. 2018;7:406-13.

30. Ferrer C, Cao P. Endovascular arch replacement with a dual branched endoprosthesis. Ann Cardiothorac Surg. 2018;7:366-71.

31. Lim CS, Dhutia A, Riga C, Dharmadasa A, Gibbs RGJ, Hamady MS. Two-vesse branched stent graft for severely angulated aortic arch aneurysm in a Jehovah's witness. Vasc Endovascular Surg. 2018;52:154-8.

32. Piffaretti G, Rivolta N, Fontana F, Carrafiello G, Mariscalco G, Castelli P. Aortic arch aneurysm repair with a new branched device. J Vasc Surg. 2013; 57:1664-7.

33. Czerny M, Rylski B, Morlock J, Schrofel H, Beyersdorf F, Saint Lebes B, et al. Orthotopic branched endovascular aortic arch repair in patients who cannot undergo classical surgery. Eur J Cardiothorac Surg. 2018;53:1007-12.

34. Kuratani T. Best surgical option for arch extension of type B dissection: the endovascular approach. Ann Cardiothorac Surg. 2014;3:292-9.

35. Shimamura K, Kuratani T, Kin K, Shijo T, Masada K, Sawa Y. Effectiveness of embolic protection filter devices in stroke prevention during endovascular aortic arch repair in significant aortic atheroma patients. Interact Cardiovasc Thorac Surg. 2019;28:974-80.

Key Words: endovascular graft, endovascular procedure, aortic arch aneurysm, stroke 